\title{
THORACIC VERTEBRAL BODY MORPHOMETRY WITH ITS CLINICAL IMPLICATIONS
}

\author{
Shweta Jha, Ruchira Sethi \\ Department of Anatomy, Heritage Institute of Medical Sciences, Varanasi, UP, India
}

\begin{abstract}
Introduction: Vertebral body morphometry is required for designing of customised bone grafts and implants for various spinal procedures. The literature review revealed number of studies focussing on the morphometry of pedicles and spinous processes of vertebrae. However there is paucity of literature for the complete dimensions of thoracic vertebral bodies. The aim of the present study was thus, to collect baseline morphometric data of thoracic vertebra in Eastern belt of Uttar Pradesh.

Material \& Methods: One hundred and fifty typical thoracic vertebrae of undetermined age and gender were selected for the study. Parameters namely anteroposterior diameter, width, anterior height, posterior height, superior transverse diameter and inferior transverse diameter of vertebral body were measured using a digital Vernier calliper. Data was analysed statistically using SPSS 19 software
\end{abstract}

Results: The mean values for anterior height, posterior height, superior transverse diameter, inferior transverse diameter, width and anteroposterior diameter were $17.06 \pm 1.52 \mathrm{~mm}, 18.13 \pm 1.64 \mathrm{~mm}, 25.32 \pm 2.32 \mathrm{~mm}, 26.97 \pm 2.40$ $\mathrm{mm}, 23.52 \pm 2.77 \mathrm{~mm}$ and $19.95 \pm 3.81 \mathrm{~mm}$ respectively.

Conclusion: Study highlights the importance of collecting morphometric data for a specific population due to diversity in geographical factors affecting morphometry.

Keywords: Thoracic vertebra, morphometry, anterior thoracic fusion, anterior height, posterior height, vertebral body width.

\section{INTRODUCTION}

The adult vertebral column is a curved linkage of 33 individual bones or vertebrae stacked one above the other in caudal cranial direction. The column protects the underlying spinal cord along with their meninges and nutrition providing intricate vasculature. The column also provides stability with limited mobility and the surface for muscular attachments [1].

Surgical procedures on the vertebral column are commonly performed for various spinal and vertebral column diseases. Anterior thoracic fusion is performed in operative treatment of osteomyelitis, fractures and various malignancies involving thoracic vertebral bodies, degenerative diseases and for correction of scoliosis [2]. It is a procedure where a surgeon applies bone grafts between two vertebral elements initiating a biological reaction inciting bone growth further this aids in healing. It is believed that pathologies like spondylolisthesis and disc abnormalities respond better when operated anteriorly [3,4]. The advantage of anterior approach is that it allows excellent view and accessibility to thoracic spine, intervertebral discs and even nerve roots. This procedure helps in relieving compression from neural elements and attains maximum spinal stability. Other advantages are direct access to lesion with minimal per operative bleed. Also the devices used for fixation have the advantage of being short segment permitting acceptable mobility [5].

The prognostic outcomes of anterior thoracic fusion procedures can be improved by designing bone grafts and appropriate implants customized as per the morphometric data of an individual/population as this

Address for Correspondence:

Dr Ruchira Sethi, Associate Professor, Department of Anatomy, Heritage Institute of Medical Sciences, Bhadwar, NH2 bypass, Varanasi, UP, India. Mob: 9873621520 Email: ruchirasethi@gmail.com 
is racial, gender and region specific.

Kunkel et al. (2011) in their study on German population studied the height of intervertebral discs at all thoracic spinal levels and emphasized that vertebral height dimensions can be a good predictor of disc height at that specific level [6]. The disc height measurements are invariably used during disc arthroplasty procedures. This further highlights the significance of obtaining vertebral body dimensions as predictors for disc disease.

The literature published till date has focussed on dimensions of thoracic spine and pedicle measurement [6-8]. There is very little literature citing the racial differences within the vertebral body measurements [8]. The present study is thus an attempt to define the morphometry of thoracic vertebral body in the studied population, this would aid in collecting an important database for regional population (Eastern belt of Uttar Pradesh).

\section{MATERIALS AND METHODS}

One hundred and fifty undamaged typical human thoracic vertebrae were selected for the study. The vertebrae were obtained from the bone bank of the Department of Anatomy, Heritage Institute of Medical Sciences, Varanasi, UP, India. The vertebrae were of undetermined gender and age and each of them was assigned a specific number. To study the morphometry, the following measurements were taken using a Vernier calliper $[9,10]$.

The following parameters were recorded in a proforma:

1. Anterior height of the body $\left(A H V_{B}\right)$ : It is the vertical distance between superior and inferior borders of vertebral body in the midsagittal plane anteriorly (Fig. 1A).

2. Vertebral body width $\left(\mathrm{WV}_{\mathrm{B}}\right)$ : It is the minimum transverse distance across the waist of vertebral body (Fig. 1A).

3. Posterior height of the body $\left(\mathrm{PHV}_{\mathrm{B}}\right)$ : It is the vertical distance between superior and inferior borders of vertebral body in the midsagittal plane posteriorly (Fig. 1B).

4. Anteroposterior diameter of the vertebral body $\left(A P V_{B}\right)$ : It is the length between anterior border and posterior border of the superior surface of vertebral body in midline (Fig.1C).
5. Superior transverse diameter of the vertebral body $\left(T D_{S} V_{B}\right)$ : It is the maximum transverse diameter of the vertebral body at the superior surface (Fig. 1C).

6. Inferior transverse diameter of the vertebral body $\left(T D_{1} V_{B}\right)$ : It is the maximum transverse diameter of the vertebral body at the inferior surface (Fig. 1D).

The data analysis was done using SPSS 19 software and the results were compared accordingly. The level of significance was noted at $p<0.05$ at $95 \%$ confidence interval.

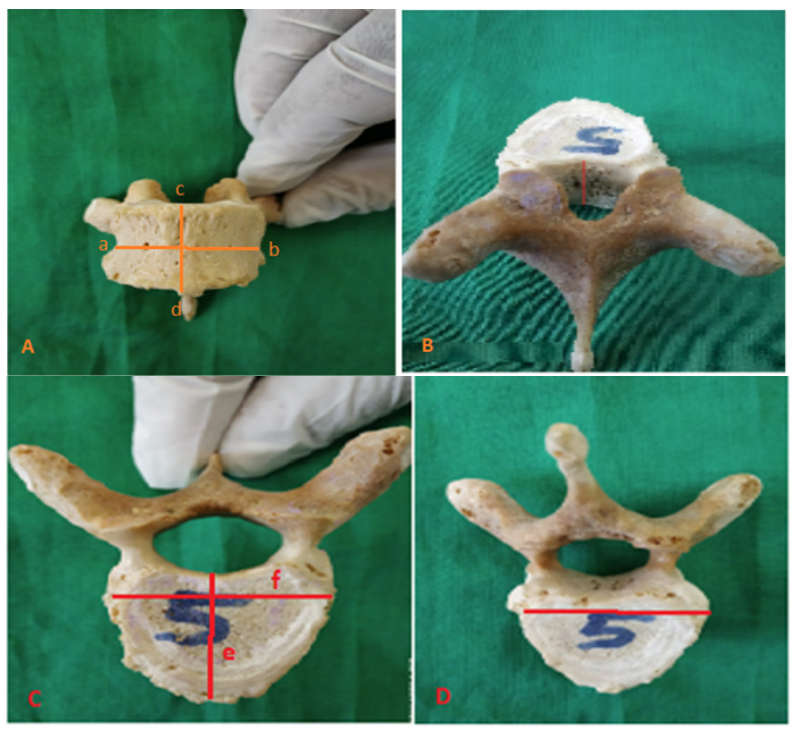

Fig. 1: Photograph showing morphometric measurements taken in the present study. $A: a b=$ vertebral body width $\left(W_{B}\right)$, cd=anterior height $\left(A H V_{B}\right), B$ : posterior height $\left(\mathrm{PHV}_{\mathrm{B}}\right)$, C: anteroposterior diameter of vertebral body (e) and superior transverse diameter (f), $D$ : inferior transverse diameter $\left(T D_{1} V_{B}\right)$

\section{RESULTS}

The observations for all parameters were assessed and are represented graphically as under. The values for anterior and posterior heights provided a range of $13.2-20.5 \mathrm{~mm}$ and $14.0-23.0 \mathrm{~mm}$ respectively, the mean and standard deviation were analysed (Fig. 2A). The superior and inferior transverse diameter of the vertebral body gave a mean range of 22.0-29.6 mm and $24.0-31.0 \mathrm{~mm}$ respectively, which are graphically represented in Fig. 2B. The vertebral body width (mean range $18.0-28.0 \mathrm{~mm}$ ) and antero-posterior diameter of vertebral body (mean range 13.0-27.0mm) are represented in Fig $2 \mathrm{C}$. The means of all the parameters were compared with that of other population groups (Fig. 3). 

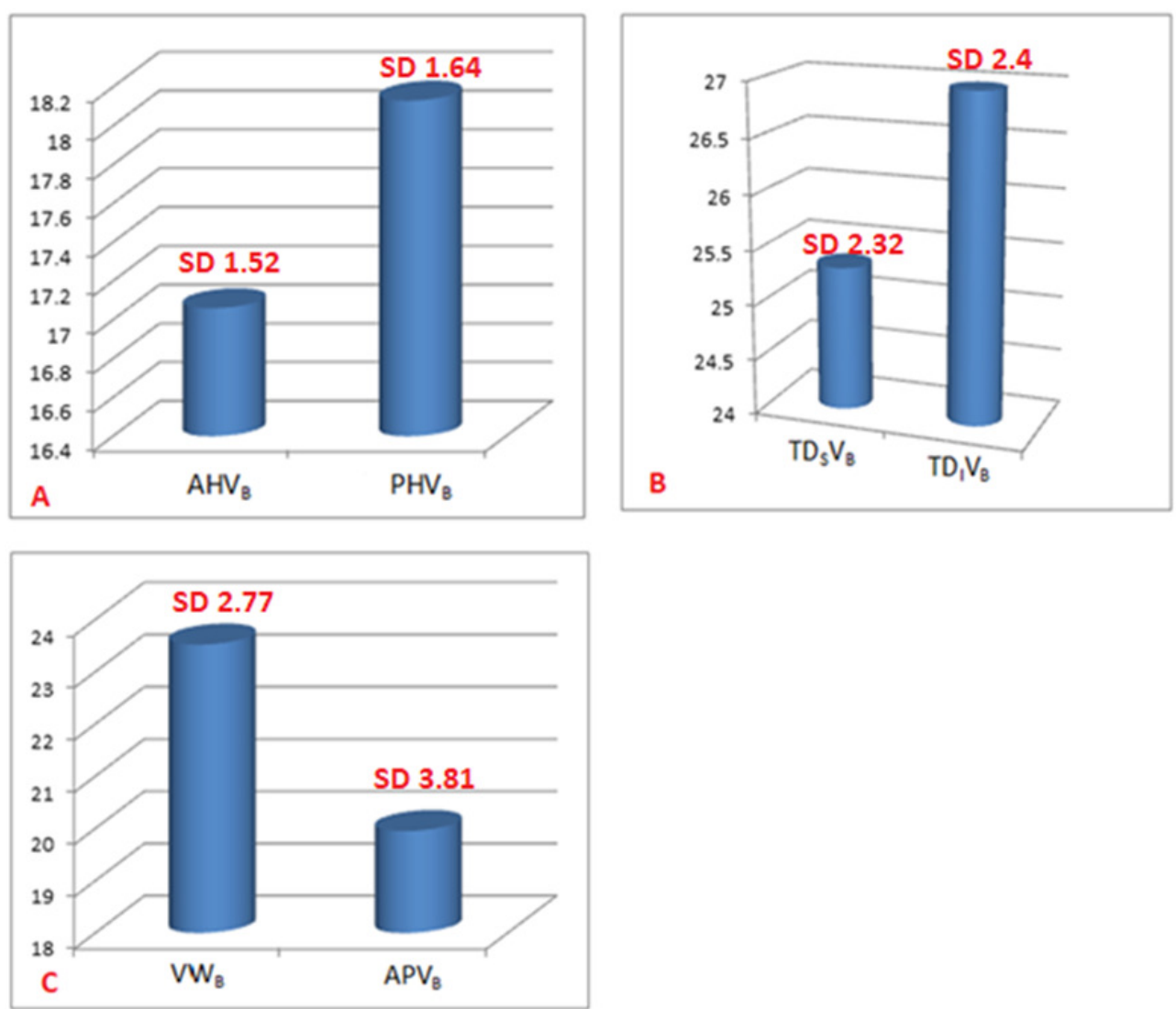

Fig. 2: Graph showing mean values of various parameters in $\mathrm{mm}$ with standard deviations

A: anterior $\left(A H V_{B}\right)$ \& posterior height $\left(\mathrm{PHV}_{\mathrm{B}}\right)$ of vertebrae $\mathrm{B}$ : superior $\left(\mathrm{TD}_{\mathrm{S}} \mathrm{V}_{\mathrm{B}}\right)$ \& inferior transverse diameter of the vertebral body $\left(T_{D}, V_{B}\right) C:$ vertebral body width $\left(V_{B}\right) \&$ anteroposterior diameter of the vertebral body $\left(A P V_{B}\right)$

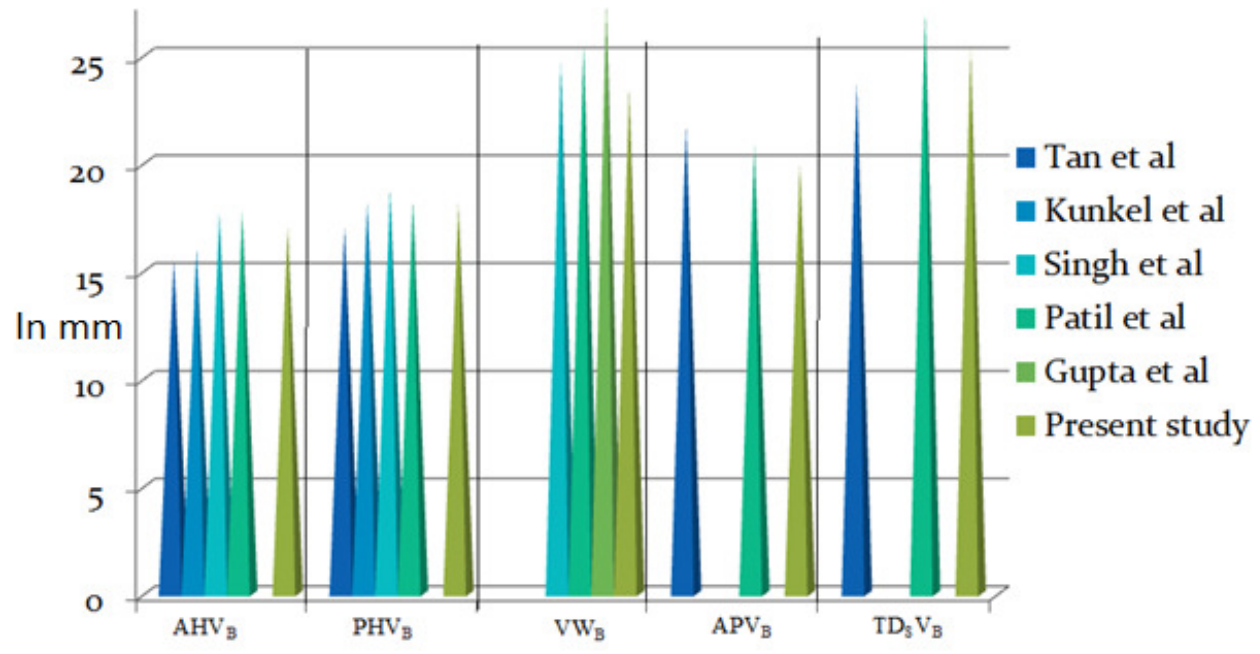

Fig. 3: Mean values of parameters compared between different population groups 


\section{DISCUSSION}

Morphology of vertebral column is affected externally by mechanical and environmental factors and internally by genetic, metabolic and hormonal factors. All these influence its ability to react to varying magnitudes of weight bearing and are much modified by occupation, locomotion and posture.

While comparing morphometric data of thoracic vertebrae of our study with that of other racial groups, it was observed that mean values of anterior vertebral height, posterior vertebral height, antero posterior diameter and superior transverse diameter were statistically significant with respect to the present study $(p<0.05)$. As per the study by Kunkel et al. (2011) on German population, their values for anterior height and posterior height were greater [6] than those from our study. Their study was primarily based on measurement of dimensions of intervertebral discs so other dimensions of body could not be extracted from their study. Comparison of the present study population with those of Chinese origin provided higher values for most of the morphometric data $\left(\mathrm{AHV}_{\mathrm{B}}, \mathrm{PHV}_{\mathrm{B}}, \mathrm{TD}_{\mathrm{S}} \mathrm{V}_{\mathrm{B}}\right.$ and $\mathrm{APV} \mathrm{B}_{\mathrm{B}}$ ) [9] (Fig. 3).

Regional comparison within Indian origin populations were also done. It was observed that there is minimal non-significant variation in vertebral body morphometry as per regional distribution. A study in Northern region conducted by Singh and Srivastava (2011) revealed higher values for anterior height, posterior height and antero-posterior diameter [8] than that of our study. Similar study on western Indian population also reported values that were greater than our study [10], though in both the studies the $p$ value was found to be statistically non-significant with that of present study (Fig. 3). The present sample was obtained from the eastern part of Uttar Pradesh.

Vertebral body width is the only parameter which was significantly variable between various population groups. Both racial (between population groups of different origin) and regional (different parts within India) differences were observed in this variable of vertebral morphometry, as has been observed by earlier researchers also [7-10]. During designing of implants for spinal instrumentation this particular variable (VW) should be taken into consideration for better post-operative prognosis.

Findings from present study highlight that morphometric data varies within population groups. Hence, spinal implants required for anterior thoracic fusion procedures need to be customised according to specific population for which a complete database is necessary. Such customisation will be instrumental in improving outcome after operative interventions. Hence it is imperative to measure the vertebral body dimensions and build an extensive database for a specific population.

\section{CONCLUSION}

This study highlights the significance of collecting baseline data for vertebral body morphometry of thoracic vertebra for different population groups as there are diverse ethnic and environmental factors modifying the vertebral morphometry.

\section{REFERENCES}

1. Standring S. Gray's Anatomy- The anatomical basis of clinical practice. The Back. $40^{\text {th }}$ ed., London: Elsevier Churchill Livingstone. 2008; 712.

2. De Giacomo T, Francioni $F$, Diso D, Tarantino R, Anile M, Venuta F, Coloni GF. Anterior approach to the thoracic spine. Interact Cardiovasc Thorac Surg. 2011; 12 (5): 692-695.

3. Mercer W. Spondylolisthesis: With a description of a new method of operative treatment and notes of ten cases. Edinb Med J. 1936; 43 (9): 545-572.

4. Speed K. Spondylolisthesis: Treatment by anterior bone graft. Arch Surg. 1938; 37:175-189.

5. Gokaslan ZL, York JE, Walsh GL, McCutcheon IE, Lang FF, Putnam JB Jr, Wildrick DM, Swisher SG, Abi-Said D, Sawaya R. Transthoracic vertebrectomy for metastatic spinal tumors. J Neurosurg. 1998; 89 (4):599-609.

6. Kunkel ME, Herkommer A, Reinehr M, Böckers TM, Wilke HJ. Morphometric analysis of the relationships between intervertebral disc and vertebral body heights: an anatomical and radiographic study of the human thoracic spine. J Anat. 2011; 219 (3):375-387.

7. Gupta T, Singla R. Thoracolumbar neural canal: A morphometric and morphological study in North Indian population. J Pharm Biomed Sci. 2011; 11 (20):1-8.

8. Singh R, Srivastva SK, Prasath CS, Rohilla RK, Siwach R, Magu NK. Morphometric measurements of cadaveric thoracic spine in Indian population and its clinical applications. Asian Spine J. 2011; 5 (1):20-34.

9. Tan SH, Teo EC, Chua HC. Quantitative three-dimensional anatomy of cervical, thoracic and lumbar vertebrae of Chinese Singaporeans. Eur Spine J. 2004; 13 (2):137-146.

10. Patil DK, Pritha BS. A morphometric study of the vertebral body in dry human typical thoracic vertebrae. International Journal of Anatomy Physiology and Biochemistry. 2014; 1(1):24-28. 